\title{
Fórum \\ O tema das competências nas atividades da ENAP
}

Desenvolver competências de dirigentes do setor público é a missão da Escola Nacional de Administração Pública (ENAP). Isso tem significado o desenvolvimento de programas de formação e capacitação em temas de gestão e liderança que integrem conhecimento teórico com habilidades e atitudes nas atividades de planejamento, execução e monitoramento de políticas públicas. O 1ํFórum sobre Gestão por Competências na Administração Pública Federal realizado nos dias 17 e 18 de fevereiro deste ano, pela Secretaria de Recursos Humanos (SRH) do Ministério do Planejamento, Orçamento e Gestão (MP) - foi um momento de partilhar os avanços e desafios ainda por vencer, nesse tema, junto a outras instituições da administração pública federal ${ }^{1}$.

As escolas de governo têm como premissa apoiar o desenvolvimento de servidores públicos nas suas principais funções, concorrendo para que as boas práticas sejam repassadas entre gerações e, especialmente, entre servidores que se movimentam pelos diversos órgãos de Estado e carreiras. As mudanças nos cargos levam à necessidade de ampliar conhecimentos específicos sobre a missão 
das instituições, sobre as formas de concorrer para aperfeiçoar a gestão das políticas em curso e de melhor atender às novas demandas que a sociedade coloca para os dirigentes. Embora não seja completamente formado por servidores de carreira, estes já são a maior parte $(71 \%)$ do quadro de servidores públicos que ocupam cargos de direção e assessoramento na administração pública federal, principal público da Escola. São as novas demandas dessas entidades e seus servidores que induzem a ENAP a pesquisar e adaptar novas tecnologias de ensino em métodos administrativos, bem como integrá-los para possibilitar a melhora do gasto público.

A Política Nacional de Desenvolvimento de Pessoal (Decreto no 5.707/2006) tornou claro o papel da ENAP não apenas como executora da capacitação dos servidores, mas como coordenadora de ações de capacitação das escolas federais de governo e das demandas dos demais órgãos federais, notadamente aqueles responsáveis pela capacitação de servidores que trabalham diretamente com a população - como os das áreas de saúde, segurança, fiscalização tributária, previdenciária, diplomática. Embora necessária, a colaboração entre escolas necessita avançar na criação de uma visão comum sobre o papel que a capacitação pode exercer no apoio às organizações públicas e aos servidores que nelas atuam, reafirmando áreas de excelência e preenchendo lacunas decorrentes de novas necessidades de formação.

A construção dessa visão sobre o papel da capacitação depende de forma crucial das estratégias adotadas em cada instituição para alcançar sua missão. Exige ainda que o mapeamento das competências individuais, passíveis de serem desenvolvidas pela capacitação, seja precedido da definição dos objetivos que cada órgão postula para si mesmo. Essas ações são fundamentais para que as instituições passem a demandar capacitação para grupos de funcionários, em vez de dar continuidade à situação usual em que a definição do desenvolvimento individual estava a cargo exclusivamente do servidor, sem que isso estivesse conectado a uma demanda institucional explícita, que revertesse em melhora de processos das equipes.

Sem dúvida, ainda há muito espaço para as decisões individuais de desenvolvimento pela ampliação da capacitação, mas cresce o incentivo para que as instituições, por meio de seus dirigentes, em particular dos responsáveis pelas áreas de recursos humanos, passem a ser os principais demandantes da capacitação, tal como ocorre em países em que a gestão de talentos está implantada e responde pela qualidade de serviços públicos.

As mudanças associadas a esse tipo de transformação no uso da capacitação para apoiar a melhora da gestão de talentos decorre de uma compreensão cada vez mais detalhada do que se espera como atitudes, habilidades e conhecimentos dos servidores públicos, sejam estes conhecimentos transversais ou específicos. Um dos aspectos que facilitam o entendimento dessa mudança está associado à capacidade crescente de definir quais são os desafios estratégicos a serem enfrentados pelos diferentes órgãos e atribuir aos dirigentes públicos, tal como é feito com os dirigentes privados, o papel de protagonistas na gestão da mudança.

No caso brasileiro, alguns desafios administrativos são conhecidos e envolvem retomar a capacidade de planejamento e integração, destacando-se:

- Integração do ambiente institucional e com objetivos socialmente desejáveis; 
- Missão e objetivos estratégicos compartilhados;

- Flexibilidade na organização do trabalho - com equipes multidisciplinares, maior horizontalidade e redesenho de processos;

- Gestão de recursos;

- Autonomia e responsabilização;

- Compromisso com a gestão do conhecimento.

No que diz respeito aos desafios da gestão de pessoas, no entanto, as dificuldades associadas à estruturação das áreas de recursos humanos e à sua legitimação junto aos dirigentes da administração pública prejudicam sua capacidade de implementar uma política mais articulada, na qual o ciclo de gestão seja observado em seu conjunto. Isso significa considerar os procedimentos de recrutamento, passando pelos de seleção, os de estruturação de carreiras e salários, os de formação permanente e os de aposentadoria.

Nesse sentido, permanece latente a tensão entre como atrair talentos jovens, com melhores perspectivas, se os processos de recrutamento e seleção consideram apenas conhecimentos teóricos e não permitem que outros aspectos sejam cotejados, de modo a possibilitar que as pessoas sejam alocadas, tanto no momento inicial quanto ao longo da carreira, a partir do melhor aproveitamento de suas competências.

De fato, embora a legislação tenha indicado que as competências são o aspecto básico a considerar na gestão de pessoas, pouco se avançou no sentido de compreender o significado dessa mudança - mesmo nas áreas responsáveis pelo processo, isto é, nas coordenações de recursos humanos. O Fórum reforçou a percepção, para vários atores que atuam com o tema das competências, da importância de dar maior visibilidade aos processos que permitem às instituições avaliarem suas necessidades e de tornar mais explícitos os procedimentos e critérios que conectem carreiras e a formação e capacitação de pessoal. Esse é o objetivo deste pequeno relato: contar realizações da Escola na área da capacitação por competências.

\section{A experiência recente da ENAP}

O compromisso da ENAP com a capacitação orientada por competências atende não só à diretriz de apoio à difusão e implantação da Política Nacional de Desenvolvimento de Pessoal (Decreto $\mathrm{n}^{\circ}$ 5.707/2006), mas, sobretudo, à sua própria missão, que se sustenta no desenvolvimento de competências de servidores públicos para aumentar a capacidade de governo na gestão das políticas públicas.

Tal missão foi definida em 2003 e já trabalha com a noção de competência, ainda que de forma muito tímida. As cooperações internacionais da ENAP, especialmente com o Canadá e a França, trouxeram a discussão de competências para a Escola, instigando cada vez mais o debate interno sobre o tema. Entre 2003 e 2006, a ENAP atuou em três frentes: na formação inicial e em cursos de aperfeiçoamento; no desenvolvimento gerencial; e na formação de seus quadros.

$\mathrm{Na}$ formação inicial e no aperfeiçoamento, a Escola incorporou as competências desejadas para servidores no desenho de cursos para as carreiras do ciclo de gestão, desde 2004, tendo por base o conhecimento acumulado na preparação de mais de 11 ciclos $^{2}$. E continuamente vem trabalhando no sentido de garantir que os cursos de aperfeiçoamento oferecidos 
tenham adesão às questões práticas que os gestores das carreiras de EPPGG (Especialistas em Políticas Públicas e Gestão Governamental) e APO (Analistas de Planejamento e Orçamento) lidam em suas funções, buscando assegurar que seu desenvolvimento acompanhe as necessidades demandadas pelas políticas públicas.

Em relação aos programas de capacitação gerencial, as experiências foram sendo ampliadas com o desenvolvimento de atividades metodológicas e experiências concretas. De 2004 a 2008, a ENAP realizou 55 oficinas de mapeamento de competências, com 600 servidores capacitados.

Um primeiro conjunto de atividades ocorreu no formato cursos e oficinas, que abordam o tema das competências junto às equipes de recursos humanos. Para esse público foram preparados os cursos de Gestão por Competências, que inclui a Oficina de Metodologias de Mapeamento de Competências; de Elaboração de Planos de Capacitação; de Gestão Estratégica de Pessoas e Planos de Carreira; e de Atendimento ao Cidadão.

Outra inovação se refere aos cursos do Programa Desenvolvimento de Gerentes Operacionais e Supervisores (DGOS) e de Gestão de Convênios e de Contratos de Repasse, reformulados em sua concepção e revistos sob a ótica das competências, como se verifica a seguir:

Gestão por Competências - curso presencial com 8 horas de duração destinado à aquisição de conhecimentos básicos sobre o tema. O público-alvo envolve coordenadores gerais, coordenadores e equipes técnicas das áreas de recursos humanos. O curso utiliza, como recursos metodológicos, a exposição dialogada e exercícios práticos, que incluem a Oficina Metodologia de Mapeamento de Competências, evento presencial com 16 horas destinado aos coordenadores e técnicos dos setores de recursos humanos e áreas afins. É estruturado para permitir uma abordagem diversificada de alternativas metodológicas e técnicas para o mapeamento de competências. Tem como propósito capacitar as organizações públicas para que possam realizar seus mapeamentos de forma autônoma, observando suas especificidades e dinâmica interna.

Elaboração de Planos de Capacitação - curso presencial com 32 horas de duração destinado aos coordenadores e técnicos que trabalham com planos e projetos de capacitação nas organizações públicas. $\mathrm{O}$ curso pretende, por intermédio de aulas expositivas e exercícios, orientar e instruir os participantes na elaboração de planos de capacitação.

Gestão Estratégica de Pessoas e Planos de Carreira - curso a distância com duração de 20 horas, destinado aos servidores públicos que lidam com a gestão de pessoas. O curso apresenta em destaque a relação entre gestão de competências e planos de carreira.

Atendimento ao Cidadão - curso a distância com duração de 20 horas destinado a todos os servidores públicos federais. O propósito é permitir aos participantes uma visão sistêmica do atendimento nas organizações públicas, com destaque para a identificação das competências essenciais a um atendimento eficiente, pautado em princípios éticos e com elevado padrão de qualidade.

Além disso, a ENAP estabeleceu, como diretriz em seu planejamento estratégico, a adequação dos seus programas e cursos de catálogo ao conceito de competência. Desde então, a Diretoria de Desenvolvimento Gerencial (DDG) tem realizado revisão dos seus cursos mediante a identificação das competências do público- 
alvo, da adequação dos objetivos instrucionais e das metodologias de ensino. Nos anos de 2006 e 2007, foi realizada a revisão do Programa de Desenvolvimento de Gerentes Operacionais e Supervisores (DGOS) e, atualmente, encontra-se em andamento a adequação do curso Gestão de Convênios e de Contratos de Repasse.

A DDG recebe com frequência demandas para a elaboração de programas de capacitação, em geral destinados aos níveis gerenciais, capazes de refletir as especificidades e necessidades das organizações demandantes. Para atender a esse tipo de encomenda, a diretoria estabeleceu a realização do mapeamento de competências como atividade prévia à elaboração dos programas. Para tanto, após a análise da demanda, são estabelecidas estratégias de mapeamento que podem incluir diversos métodos e técnicas, isoladas ou combinadas, a exemplo da pesquisa com grupo focal, entrevistas estruturadas ou survey.

O mapeamento e os programas de capacitação, considerando as competências a serem adquiridas ou reforçadas, foram desenvolvidos para organizações como o Instituto Nacional de Metrologia (Inmetro), com o objetivo de capacitar todo o seu quadro de dirigentes, e também para os institutos federais de Educação, Ciência e Tecnologia (Ifets), para formar os dirigentes considerando as novas necessidades do ensino médio técnico e sua inserção no mundo do trabalho. Participaram desse processo 10 entidades: Presidência da República; Ministério do Turismo; Ministério da Educação; Departamento Nacional de Infraestrutura de Transportes (DNIT); Ministério da Saúde; Ministério do Desenvolvimento, Indústria e Comércio Exterior (MDIC); Agência Nacional de
Transportes Terrestres (ANTT); Ministério da Previdência e Assistência Social (MPAS); Ministério do Trabalho e Emprego (MTE); Ministério do Planejamento, Orçamento e Gestão (MP).

Entre os projetos desenvolvidos pela DDG a partir de 2007, destacam-se as oficinas para mapear e validar as competências do cargo de subsecretário das subsecretarias de Planejamento, Orçamento e Administração (SPOA). O resultado desse mapeamento encontra-se em fase de validação e, em seguida, embasará a formulação de um plano de capacitação para os dirigentes das subsecretarias, que deverá ser implementado ainda em 2009. Outro projeto importante foi o Programa de Capacitação para o Departamento de Coordenação e Controle das Estatais (Dest), ainda em avaliação.

\section{Novas Metodologias: Mesa- redonda de Pesquisa-Ação (MRPA)}

Desde 2004, a ENAP pesquisa sobre Gestão por Competências de forma colaborativa, utilizando a metodologia Mesa-redonda de Pesquisa-Ação, com participação de especialistas e gestores das principais instituições da administração direta e indireta ${ }^{3}$.

A Mesa-redonda "Gestão por competências em organizações de governo", que gerou um livro, realizou-se em 2004 e 2005. Seus principais objetivos foram: a) permitir a difusão de conhecimentos sobre gestão por competências e a reflexão sobre os limites e possibilidades do uso dessa nova abordagem em atividades de gestão de recursos humanos nas organizações de governo brasileiras; b) desenvolver um produto que possa ser útil aos técnicos e gestores envolvidos com atividades de gestão de pessoas em organizações do Executivo Federal ${ }^{4}$. 
Em 2008, a ENAP realizou a Mesaredonda de Pesquisa-Ação "Escolas de Governo e Gestão por Competências", focada nas implicações do referencial de competências para a formação e capacitação de servidores. Presidida pelo diretor da Escola Nacional de Saúde Pública Sérgio Arouca (ENSP/Fiocruz), Antônio Ivo de Carvalho, a Mesa teve a ENAP como secretaria-executiva dos trabalhos ${ }^{5}$. Os principais temas debatidos foram as metodologias para elaboração de cursos e programas a partir do referencial de competências, as transformações do mundo do trabalho e o impacto na forma de atuar do setor público.

Essa Mesa-redonda de Pesquisa-Ação teve como objetivos:

a) permitir a apropriação de conhecimentos sobre gestão por competências e a reflexão sobre a possibilidade de utilização dessa abordagem na capacitação de servidores públicos brasileiros;

b) debater questões e esclarecer dúvidas que surgirem ao longo do desenvolvimento dos trabalhos;

c) identificar e explorar experiências recentes na aplicação da gestão por competências no subsistema de capacitação e treinamento; e

d) construir coletivamente um produto prático que possa ser utilizado em ambientes de trabalho das escolas. Como resultado foi elaborado o livro "Escolas de governo e gestão por competências: Mesa-redonda de Pesquisa-Ação", em fase de impressão.

\section{Lições aprendidas}

O debate da introdução das competências nos processos de gestão e de capacitação está em curso, mas ainda precisa de forte divulgação e mais trocas de experiências entre os parceiros. Não obstante o esforço de difusão dos conceitos e das alternativas metodológicas para o mapeamento de competências, como recurso de sistematização dos planos de capacitação, persiste a dificuldade das organizações públicas para a adoção das práticas discutidas em cursos e oficinas.

A partir das experiências já existentes, cresce a expectativa de que será possível, em breve, ter indicações suficientes para estabelecer quais são as características comuns das carreiras públicas do nível federal e quais as competências específicas, decorrentes das diferentes inserções. Vale lembrar que isso será possível não apenas a partir de teorias, mas de construções especificamente preparadas para órgãos da administração pública federal brasileira.

Para tornar viável essa proposta, os dirigentes públicos não apenas devem participar ativamente no processo de planejamento, mapeamento e elaboração dos planos de capacitação de suas organizações, como apoiar o desenvolvimento e a legitimação das coordenações de recursos humanos como interlocutores privilegiados para a implementação da gestão por competência. As escolas de governo também podem colaborar e, com a utilização de metodologias inovadoras, apoiar atividades que auxiliem a tomada de decisão desses dirigentes. 


\section{Notas}

1 Ver https://portalsipec.planejamento.gov.br/eventos/forum-de-gestao-por-competencias.

2 Caderno ENAP 33

3 Márcia M.S. Oliveira (Aneel), Maria Izabel (Antaq), Delor Moreira (Bacen), Hugo Pena Brandão (BB), Vera Cecília Dantas (Câmara dos Deputados), Priscila Araújo (Casa Civil), Mônica Almeida (CEF), Jeter Ribeiro de Souza (CEF), Humberto Moraes (Eletronorte), Maria Alice Pessanha (ENSP/ Fiocruz), Célio Fujiwara (ENAP), Mônica Fernandes (ENAP), César Felício Prata (Embrapa), Alda Mitiê (Ministério do Trabalho), José Vitor E. Filho (Ministério da Fazenda), João Monteiro (Ministério da Justiça), Maria de Lourdes e Silva (Sebrae), Salvatore Palumbo (TCU), Tânia Gomes (CNPq), Alexandre Kalil (Seges/MP), Isamir M. de Carvalho (Serpro).

4 Ver materiais preparatórios em www2.enap.gov.br/mesa redonda e produto final www.enap.gov.br/publicações.

5 Compuseram a Mesa Anísio Soares Vieira, da Academia Nacional de Polícia (ANP); José Inácio Jardim Motta, da Escola Nacional de Saúde Pública Sérgio Arouca (ENSP); Margaret Baroni, da Escola Nacional de Administração Pública (ENAP); Maria Cristina Macdowell, da Escola de Administração Fazendária (Esaf); Fátima Bruno, da Universidade de Brasília (UnB); Rosângela Salgado, da Escola da Previdência Social; e Sérgio da Costa Côrtes, da Fundação Instituto Brasileiro de Geografia e Estatísticas (Ence/IBGE). 